\title{
Can antioxidants be effective therapeutics for type 2 diabetes?
}

\section{Soyoung Park, So-Young Park}

Department of Physiology and Smart-aging Convergence Research Center, Yeungnam University College of Medicine, Daegu, Korea

Received: July 7, 2020

Revised: August 19, 2020

Accepted: August 31, 2020

Corresponding author:

So-Young Park, MD, PhD

Department of Physiology,

Yeungnam University College of

Medicine, 170 Hyeonchung-ro,

Nam-gu, Daegu 42415, Korea

Tel: +82-53-640-6923

E-mail: sypark@med.yu.ac.kr
The global obesity epidemic and the growing elderly population largely contribute to the increasing incidence of type 2 diabetes. Insulin resistance acts as a critical link between the present obesity pandemic and type 2 diabetes. Naturally occurring reactive oxygen species (ROS) regulate intracellular signaling and are kept in balance by the antioxidant system. However, the imbalance between ROS production and antioxidant capacity causes ROS accumulation and induces oxidative stress. Oxidative stress interrupts insulin-mediated intracellular signaling pathways, as supported by studies involving genetic modification of antioxidant enzymes in experimental rodents. In addition, a close association between oxidative stress and insulin resistance has been reported in numerous human studies. However, the controversial results with the use of antioxidants in type 2 diabetes raise the question of whether oxidative stress plays a critical role in insulin resistance. In this review article, we discuss the relevance of oxidative stress to insulin resistance based on genetically modified animal models and human trials.

Keywords: Antioxidants; Insulin resistance; Oxidative stress; Reactive oxygen species

\section{Introduction}

Although reactive oxygen species (ROS) are produced as a byproduct of oxygen metabolism, they play a significant role in normal cellular functions $[1,2]$. A well-organized antioxidant system maintains the physiological levels of ROS [3]. However, an imbalance between ROS production and antioxidant capacity causes ROS accumulation, which induces chemical modifications of DNA, protein, and lipids, leading to cellular damage, known as oxidative stress [1-3].

Oxidative stress is closely linked to a variety of diseases, including type 2 diabetes [1]. Type 2 diabetes is increasing globally due to the obesity pandemic and the growth of the aging population, and insulin resistance is a critical link between these two. Insulin resistance is known to be a critical risk factor for type 2 diabetes and other chronic diseases, such as cardiovascular diseases and cancers [4]. It is known that hyperglycemia in diabetic patients leads to se- rious complications by enhancing oxidative stress in the heart, kidney, and eyes [2]. Recently, oxidative stress has also been suggested to be a cause of insulin resistance $[3,5]$. Oxidative stress is increased in the plasma and tissue of patients and experimental animals with type 2 diabetes. Genetic modulation of antioxidant enzymes in rodents also supports the causative role of oxidative stress in insulin resistance. However, the inconsistent effects of antioxidant treatment on type 2 diabetes raise the question of whether oxidative stress induces insulin resistance. Thus, we sought to identify the role of oxidative stress in the development of insulin resistance based on animal experiments and human trials.

\section{Reactive oxygen species and antioxidant systems}

ROS are defined as oxygen-containing reactive species and include superoxide anion, hydrogen peroxide, hydroxyl radical, peroxyni-

Copyright (C) 2021 Yeungnam University College of Medicine

This is an Open Access article distributed under the terms of the Creative Commons Attribution Non-Commercial License (http://creativecommons.org/licenses/by-nc/4.0/) which permits unrestricted non-commercial use, distribution, and reproduction in any medium, provided the original work is properly cited. 
trite, hypochlorous acid, and singlet oxygen [6]. The mitochondria electron transport chain, cell membrane nicotinamide-adenine dinucleotide phosphate (NADPH) oxidase, cytochrome $\mathrm{p} 450$, and xanthine oxidase are the main intracellular sites of ROS generation, and among them, mitochondria is the primary source of ROS [7].

In the mitochondria, the generated superoxide anion is converted into hydrogen peroxide superoxide dismutase 2 (SOD2). Subsequently, hydrogen peroxide is detoxified to form water in the presence of antioxidant enzymes such as glutathione peroxidase (GPx) or peroxidase or is exported to the cytoplasm (Fig. 1). Superoxide anions are also generated in the cell membrane and cytoplasm by NADPH oxidase and xanthine oxidase, respectively. In the cytoplasm, superoxide dismutase 1 (SOD1) catalyzes the conversion of superoxide anion to hydrogen peroxide, which is then detoxified to form water by enzymatic or nonenzymatic antioxidants, including glutathione, GPx, catalase, peroxiredoxin, and thioredoxin. In addition, catalase is a primary antioxidant that catalyzes hydrogen peroxide formation in the peroxisome. Oxidized methionine is reduced by methionine sulfoxide reductase in the cytoplasm, mitochondria, and endoplasmic reticulum. Moreover, peroxynitrite, produced by the reaction between nitric oxide and superoxide anion, and responsible for a wide array of tissue damage, is decomposed by peroxiredoxin, glutathione, and GPx $[8,9]$.

Even though the intracellular antioxidant system is well developed to prevent ROS accumulation, ROS production can overwhelm the antioxidant capacity and induce oxidative damage to DNA, protein, and lipids.

\section{Insulin signaling pathways}

An increase in blood glucose levels after a meal induces insulin secretion from pancreatic $\beta$-cells, which leads to glucose uptake in skeletal muscle and adipose tissue by activating intracellular insulin signaling pathways. In the liver, insulin suppresses glycogen breakdown and gluconeogenesis while increasing glucose oxidation and glycogen synthesis. Inhibition of insulin signaling pathways in these peripheral tissues results in the development of insulin resistance. In this review, we will focus on insulin resistance in skeletal muscle (Fig. 2).

Secreted insulin binds to insulin receptors on the plasma membrane and promotes autophosphorylation of tyrosine residues in the beta-subunit of the insulin receptor [10]. The activation of the insulin receptor immediately induces tyrosine phosphorylation of the insulin receptor substrate (IRS) proteins, which are initial downstream

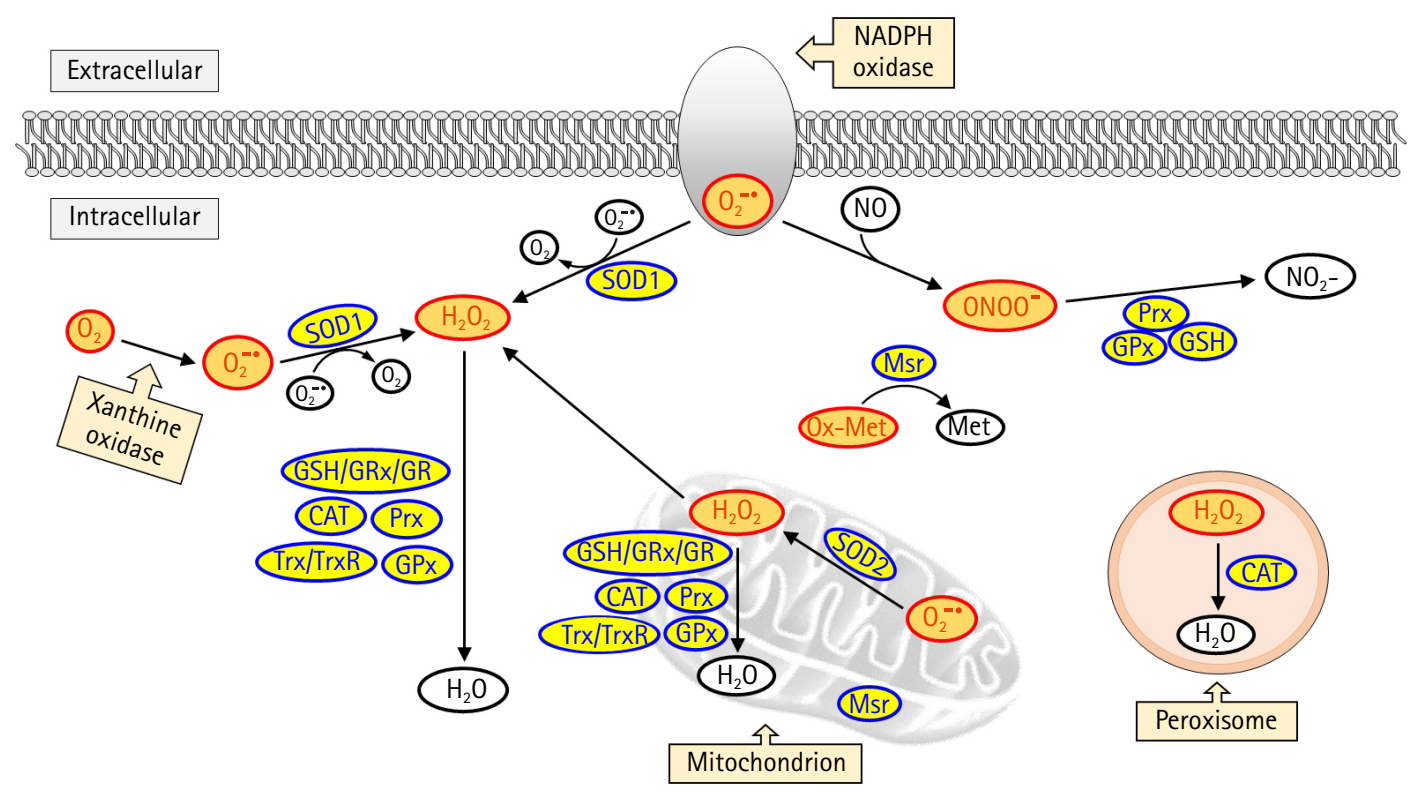

Fig. 1. Intracellular reactive oxygen species (ROS) generation and the antioxidant scavenging system. ROS is produced from mitochondria, peroxisome, nicotinamide-adenine dinucleotide phosphate (NADPH) oxidase, and xanthine oxidase. Among these sources, the mitochondrial electron transport chain is the primary source for ROS production. Superoxide dismutase 2 (SOD2) catalyzes the conversion of superoxide anion $\left(\mathrm{O}_{2}^{-}\right)$into hydrogen peroxide $\left(\mathrm{H}_{2} \mathrm{O}_{2}\right)$ in the mitochondria. The $\mathrm{H}_{2} \mathrm{O}_{2}$ is then detoxified in the mitochondria or moves to the cytoplasm. Cytoplasmic superoxide anion is generated from NADPH oxidase and xanthine oxidase, and subsequently converted into $\mathrm{H}_{2} \mathrm{O}_{2}$ by superoxide dismutase 1 (SOD1). $\mathrm{H}_{2} \mathrm{O}_{2}$ is detoxified by glutathione (GSH)/glutaredoxin (GRx)/glutathione reductase $(\mathrm{GR})$, catalase (CAT), peroxiredoxin (Prx), thioredoxin (Trx)/thioredoxin reductase (TrxR), and glutathione peroxidase (GPx). 0xidized methionine (Ox-Met) is reduced by methionine sulfoxide reductase (Msr) to methionine (Met). Nitric oxide (NO) reacts with superoxide anion to form peroxynitrite $\left(\mathrm{ONOO}^{-}\right)$, which is detoxified by $\mathrm{Prx}, \mathrm{GSH}$, and GPx. 


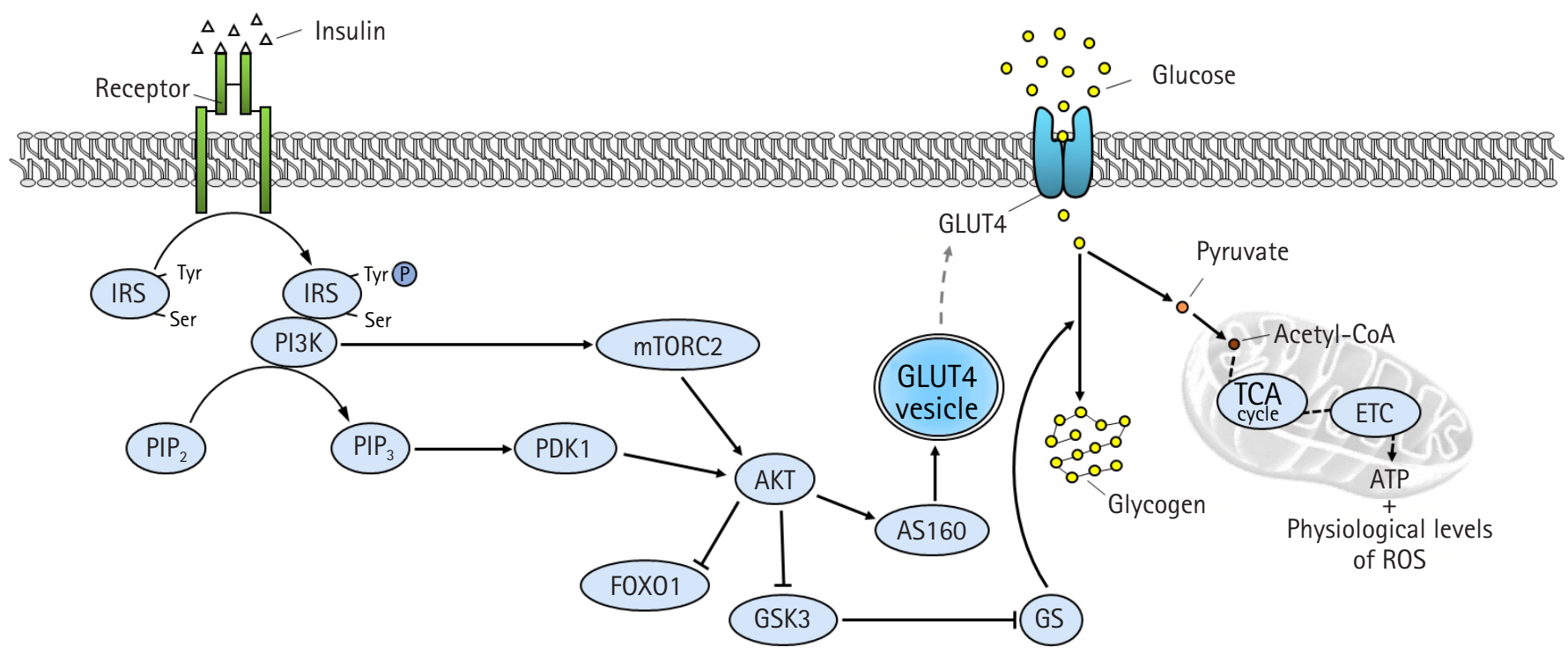

Fig. 2. Intracellular insulin signaling pathway in skeletal muscle. Binding of insulin to insulin receptors (IR) on the plasma membrane promotes tyrosine autophosphorylation at the IR, which in turn induces tyrosine phosphorylation of the IR substrate (IRS). IRS activates the downstream substrate phosphatidylinositol 3-kinases (PI3K)/protein kinase B (AKT) pathway, and the activated AKT leads to increased glucose uptake and glycogen synthesis by inducing phosphorylation of AKT substrate of $160 \mathrm{kDa}$ (AS160) and glycogen synthase kinase 3 (GSK3) respectively. Activated AS160 increases glucose uptake by mediating the translocation of glucose transporter type 4 (GLUT4) from the cytoplasm to the plasma membrane. Intracellular glucose is used for adenosine triphosphate (ATP) generation and glycogen synthesis. Tyr, tyrosine; Ser, serine; PIP ${ }_{21}$ phosphatidylinositol 4,5-bisphosphate; $\mathrm{PIP}_{31}$, phosphatidylinositol $(3,4,5)$-triphosphate; PDK1, phosphatidylinositide-dependent protein kinase 1; mTORC2, mammalian target of rapamycin complex 2; FOXO1, forkhead box protein 01; GS, glycogen synthase; acetyl-CoA, acetyl coenzyme A; TCA, tricarboxylic acid cycle; ETC, electron transport chain; ROS, reactive oxygen species.

substrates of insulin signaling [11]. Phosphorylated IRS contains binding sites for numerous signal transduction partners with Src homology 2 domains, such as phosphatidylinositol 3-kinases (PI3K) [12]. Activated PI3K generates phosphatidylinositol $(3,4,5)$-triphosphate $\left(\mathrm{PIP}_{3}\right)$ by catalyzing the phosphorylation of phosphatidylinositol 4,5-bisphosphate [13]. PIP 3 induces the activation of protein kinase $\mathrm{B}$ (AKT), which is a key divergence point in the insulin signaling pathway [14]. Activation of AKT is induced via phosphorylation of threonine and serine residues by phosphatidylinositide-dependent protein kinase 1 and mammalian target of rapamycin complex 2 [15]. Subsequently, activated AKT phosphorylates numerous downstream substrates, including forkhead box protein $\mathrm{O} 1$ (FOXO1), AKT substrate of $160 \mathrm{kDa}$ (AS160), and glycogen synthase kinase 3 (GSK3) [16]. The phosphorylation of GSK3 releases the inhibitory effect of GSK3 on glycogen synthase, leading to increased glycogen synthesis [17]. Furthermore, the phosphorylation of FOXO1 suppresses FOXO1-regulated expression of pyruvate dehydrogenase kinase 4 [18]. Phosphorylated AS160 mediates the translocation of the glucose transporter type 4 (GLUT4) from the cytoplasm to the plasma membrane [19]. This reaction ultimately completes the action of insulin by increasing glucose utilization and storage, as well as promoting glucose uptake in the tissues.

\section{Oxidative stress and insulin resistance}

The insulin-mediated signaling pathway plays a crucial role in lowering blood glucose and regulating overall glucose metabolism in vivo. A reduction in the biological effect of insulin is called insulin resistance, in which blood glucose cannot be used effectively as an energy source due to decreased insulin responsiveness of insulin-sensitive tissues such as skeletal muscle, adipose tissue, and the liver. To escape this condition, $\beta$-cells produce more insulin, but this eventually leads to $\beta$-cell exhaustion [20]. A reduction in insulin secretion due to $\beta$-cell exhaustion increases blood glucose levels, resulting in the development of type 2 diabetes [20]. Although defects in insulin receptors contribute to insulin resistance, perturbations in intracellular insulin signaling pathways are mostly responsible for insulin resistance.

Free fatty acids (FFAs) in plasma are generally supplied through lipolysis and are used as a primary energy source through $\beta$-oxidation in the liver, heart, and skeletal muscle during fasting and exercise. However, chronically elevated levels of FFAs in the plasma are one of the key triggers leading to defects in the insulin signaling pathway $[21,22]$. Increased utilization of FFAs leads to the accumulation of fat metabolites, such as fatty acyl-coenzyme A, cera- 
mides, and diacylglycerol in the liver and skeletal muscle [23-25]. High levels of fatty acid metabolites activate serine-threonine kinases, including protein kinase C (PKC), c-Jun N-terminal kinase (JNK), and inhibitory $\kappa \mathrm{B}$ kinase (IKK) $\beta$, leading to the suppression of insulin-stimulated signaling pathways [23,26,27]. Serine phosphorylation of IRS by these serine-threonine kinases inhibits tyrosine phosphorylation of IRS by insulin, eventually reducing glucose uptake [27].

Recently, fatty acid-induced oxidative stress has drawn attention as one of the causes of insulin resistance. Increased plasma levels of FFAs enhance cellular ROS production [28]. Since mitochondria are a major source of ROS, mitochondrial overload caused by an excess of substrate has been regarded as the main cause of ROS production $[29,30]$. Recently, the fatty acid metabolite, ceramide, and inflammatory cytokines have also been shown to increase mitochondrial ROS generation [31].

Similar to fatty acid metabolites, ROS also activate PKC, IKK, and JNK, leading to inhibition of IRS tyrosine phosphorylation $[28,32]$
(Fig. 3). Moreover, the activation of nuclear factor- $\kappa$ B by IKK exacerbates insulin resistance by increasing inflammatory cytokines [31]. ROS induce GLUT4 degradation by transporting GLUT4 to the lysosome instead of the plasma membrane via disruption of the retromer complex in a casein kinase 2-dependent manner [33]. In addition, peroxynitrite produced by the accumulation of nitric oxide inhibits the action of insulin by inducing the nitration of tyrosine residues and reducing the phosphorylation of IRS-1 [34]. The activation of AKT is also suppressed by peroxynitrite [35].

Increased ROS levels suppress the action of insulin by inducing mitochondrial dysfunction [36]. ROS induce mutations in the mitochondrial DNA, resulting in functional defects caused by altered expression of constituent proteins that are important for electron transport, such as complexes I, III, and IV [37]. These functional defects amplify oxidative stress and shut down mitochondrial energy production [38]. Therefore, the vicious cycle formed between ROS and mitochondria eventually leads to apoptosis.

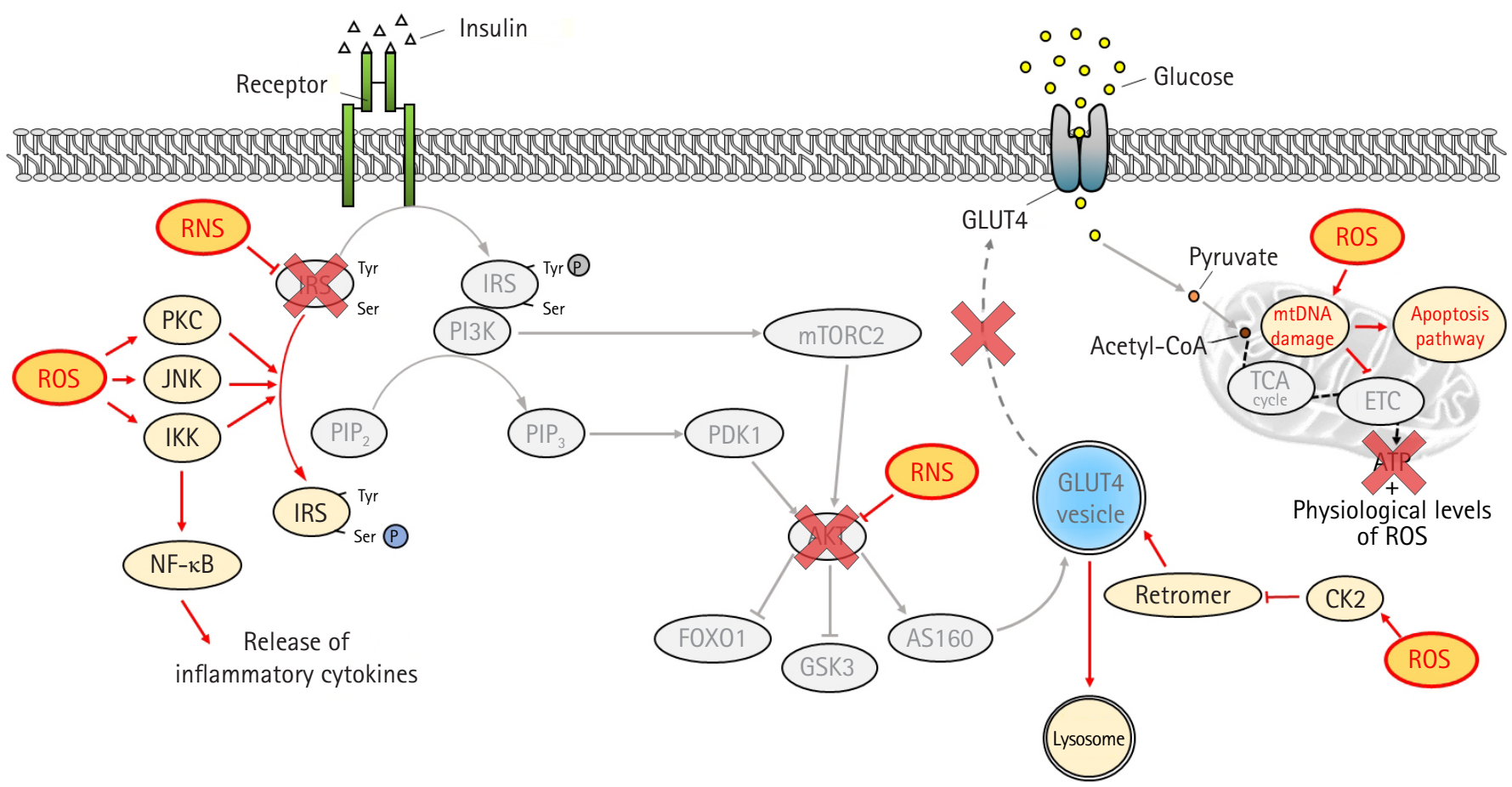

Fig. 3. Inhibition of the insulin signaling pathway by oxidative stress. Reactive oxygen species (ROS) interferes with insulin action by altering several substrates of the insulin signaling pathway. ROS activates serine/threonine kinases, including protein kinase C (PKC), c-Jun N-terminal kinase (JNK), and inhibitory $\kappa B$ kinase (IKK), which not only inhibit the activation of insulin receptor substrate (IRS) through serine phosphorylation but also induce inflammation by activating nuclear factor $\kappa B$ (NF-kB). In addition, ROS suppresses glucose absorption by degrading glucose transporter type 4 (GLUT4) in a casein kinase 2 (CK2)-dependent manner. Reactive nitrogen species (RNS) inhibits tyrosine phosphorylation of IRS and protein kinase B (AKT) activation by inducing nitration of tyrosine. Mitochondrial functional defects by ROS not only induce an explosive increase in oxidative stress but also suppress mitochondrial energy production, eventually leading to cell death. Tyr, tyrosine; Ser, serine; PIP $_{2}$, phosphatidylinositol 4,5-bisphosphate; PIP $_{3}$, phosphatidylinositol $(3,4,5)$-triphosphate; PI3K, phosphatidylinositol 3-kinases; PDK1, phosphatidylinositide-dependent protein kinase 1; mTORC2, mammalian target of rapamycin complex 2; FOX01, forkhead box protein 01; GSK3, glycogen synthase kinase 3; AS160, AKT substrate of 160 kDa; acetyl-CoA, acetyl coenzyme $A$; mtDNA, mitochondrial DNA; TCA, tricarboxylic acid cycle; ETC, electron transport chain. 


\section{Genetic modification of antioxidant enzymes and insulin sensitivity}

Obesity induced by a chronic high-fat diet (HFD) has been shown to increase oxidative stress accompanied by insulin resistance in insulin-sensitive tissues in rodents $[39,40]$. Generally, the genetic deletion of antioxidant enzymes increases oxidative stress and induces insulin resistance and/or glucose intolerance, while overexpres- sion of antioxidants reduces oxidative stress and improves insulin resistance and/or glucose intolerance (Table 1) [39-64].

However, although ROS levels have been altered by genetic modulation of antioxidant enzymes, some of the studies reported unaltered insulin sensitivity, especially in the case of SOD modulation alone (Table 1). Moreover, unexpectedly, the global knockout of GPx1 improves insulin resistance [52], whereas overexpression of GPx1 impairs insulin sensitivity [51]. Although increased ROS

Table 1. The effect of deficiency or overexpression of antioxidant enzymes on glucose metabolism and insulin sensitivity in mice

\begin{tabular}{|c|c|c|}
\hline Antioxidant & Gene modification & Metabolic phenotype \\
\hline \multirow[t]{2}{*}{ SOD1 } & Global KO & $\begin{array}{l}\text { Reduction in } \beta \text {-cell volume and insulin secretion/unaltered insulin sensitivity and increased mitochondrial hy- } \\
\text { drogen peroxide production in muscle [41] }\end{array}$ \\
\hline & Global OE & $\begin{array}{l}\text { Improved glucose intolerance and reduced skeletal muscle hydrogen peroxide generation and oxidative stress in } \\
\text { HFD-fed mice [42] }\end{array}$ \\
\hline \multirow[t]{4}{*}{ SOD2 } & Hz global KO & Impaired insulin secretion, increased ROS in islets, and unaltered insulin sensitivity [43] \\
\hline & Global OE & Improved glucose intolerance and reduced skeletal muscle oxidative stress in HFD-fed mice [42] \\
\hline & & Unaltered insulin sensitivity and reduced hydrogen peroxide generation in HFD-fed mice [44] \\
\hline & Skeletal muscle OE & Improved insulin resistance and reduced oxidative stress in the skeletal muscle of rats [45] \\
\hline \multirow[t]{5}{*}{ Catalase } & Global KO & Exacerbated HFD-induced insulin resistance and increased oxidative stress in white adipose tissue [46] \\
\hline & & Accelerated HFD-induced obesity and increased oxidative stress in white adipose tissue [47] \\
\hline & Global OE & Reduction in fat mass, oxidative stress, and glucose levels in ob/ob mice [48] \\
\hline & Mitochondrial OE & $\begin{array}{l}\text { Improved insulin resistance and reduced hydrogen peroxide generation and oxidative stress in skeletal muscle } \\
{[44,49]}\end{array}$ \\
\hline & & $\begin{array}{l}\text { Improved insulin resistance and reduced hydrogen peroxide generation and lipid accumulation in the skeletal } \\
\text { muscle of HFD-fed mice [50] }\end{array}$ \\
\hline $\begin{array}{l}\text { SOD2 and } \\
\text { catalase }\end{array}$ & $\begin{array}{l}\text { Global SOD2 OE and } \\
\text { mitochondrial catalase } \\
\text { OE }\end{array}$ & $\begin{array}{l}\text { Improved insulin resistance and reduced hydrogen peroxide generation and oxidative stress in skeletal muscle. } \\
\text { No difference in insulin sensitivity or hydrogen peroxide generation compared with that of mitochondrial cat- } \\
\text { alase OE only [44] }\end{array}$ \\
\hline \multirow[t]{3}{*}{ GPx1 } & Global OE & Increased fat mass and the development of insulin resistance [51] \\
\hline & Global KO & Improved insulin resistance, enhanced production of ROS and oxidation of PTP [52] \\
\hline & Liver KO & Improved insulin sensitivity, increased hydrogen peroxide generation in hepatocyte and oxidation of PTP [53] \\
\hline $\begin{array}{r}\text { GPx1 and } \\
\text { catalase }\end{array}$ & Global KO & Prevention of obesity, improved glucose tolerance, and attenuated nonalcoholic fatty liver in HFD-fed mice [54] \\
\hline GRx2 & Global KO & Exacerbated obesity and insulin resistance in HFD-fed mice/exacerbated oxidative stress by HFD in brain [55] \\
\hline \multirow[t]{3}{*}{ Prx2 } & Global KO & Exacerbated aging-induced insulin resistance and oxidative stress in muscle [56] \\
\hline & & Prevented obesity and insulin resistance in HFD-fed mice [57] \\
\hline & & $\begin{array}{l}\text { Reduced insulin sensitivity and increased oxidative stress in control diet/no effect on oxidative stress and insu- } \\
\text { lin resistance in HFD-fed mice [58] }\end{array}$ \\
\hline \multirow[t]{2}{*}{ Prx3 } & Global KO & $\begin{array}{l}\text { Induced obesity, increased oxidative stress, and impaired glucose tolerance and insulin sensitivity/increased su- } \\
\text { peroxide levels in 3T3-L1 adipocytes [59] }\end{array}$ \\
\hline & Global OE & Reduced mitochondrial hydrogen peroxide levels and oxidative stress and improved glucose intolerance [60] \\
\hline Prx4 & Global OE & $\begin{array}{l}\text { Improved glucose intolerance in STZ mice and reduced oxidative stress and steatohepatitis in HFD-fed STZ mice } \\
\text { [61] }\end{array}$ \\
\hline $\operatorname{Prx6}$ & Global KO & Reduced insulin secretion and impaired glucose tolerance and insulin sensitivity [62] \\
\hline \multirow[t]{3}{*}{ MsrA } & Global KO & Impaired glucose tolerance and exacerbated insulin resistance and oxidative stress in HFD-fed mice [63] \\
\hline & Mitochondrial OE & Improved insulin resistance in HFD-fed mice/preserve insulin sensitivity without cytosolic MsrA [64] \\
\hline & Cytoplasmic OE & Unaltered insulin resistance in HFD-fed mice [64] \\
\hline MsrB1 & Global KO & No effect on insulin sensitivity, hydrogen peroxide levels, or oxidative stress in HFD-fed mice [40] \\
\hline SelW & Global KO & No change in oxidative stress or insulin sensitivity in the skeletal muscle of HFD-fed mice [39] \\
\hline
\end{tabular}

SOD1, superoxide dismutase 1; SOD2, superoxide dismutase 2; KO, knockout; OE, overexpression; HFD, high-fat diet; Hz, heterozygous; ROS, reactive oxygen species; GPx, glutathione peroxidase; PTP, protein-tyrosine phosphatase; GRx, glutaredoxin; Prx, peroxiredoxin; STZ mice, streptozotocin-injected mice; Msr, methionine sulfoxide reductase; SelW, selenoprotein W. 
levels have been known to suppress insulin signaling pathways through activation of serine/ threonine kinases $[65,66]$, paradoxical activation of insulin signaling pathways by ROS through oxidation of protein-tyrosine phosphatase $1 \mathrm{~B}$ has been reported in GPx1-knockout mice [52]. Therefore, increased ROS may be associated with a combination of both favorable and unfavorable effects on insulin sensitivity.

In addition to the results of genetically modified mouse models, the treatment of experimental animals with antioxidants, such as hemin, glutathione, vitamin C, and polyphenols, has been reported to improve insulin resistance [67-70], suggesting that a reduction in oxidative stress could be a potential therapeutic approach for type 2 diabetes.

\section{Oxidative stress in patients with type 2 diabetes}

There is a large body of evidence indicating that oxidative stress is increased in the plasma or blood cells of diabetic patients. Compared with those in healthy glucose-tolerant individuals, the levels of biomarkers of oxidative damage to proteins [71,72], lipids [73-76], and DNA [74,77], such as carbonyl groups, malondialdehyde, thiobarbituric acid reactive substances, and 8-hydroxydeoxyguanosine, are increased in patients with type 2 diabetes. Moreover, these biomarker levels are positively correlated with hemoglobin Alc (HbA1c) or homeostatic model assessment for insulin resistance (HOMA-IR) in patients with type 2 diabetes [76-79], suggesting a close link between insulin resistance and oxidative stress.

Oxidative stress is higher in patients with diabetes than in healthy individuals, not only in the plasma but also in insulin-sensitive peripheral tissues, including skeletal muscles. Higher levels of biomarkers of DNA oxidation [80] and lipid oxidation [81] have been reported in skeletal muscle tissues of diabetic patients as compared to healthy controls. Lipid peroxidation levels are negatively correlated with glucose disposal [81]. Moreover, in a previous study assessing nitrosative stress in diabetes, nitrites and nitrates were increased in quadriceps muscle of diabetic patients as compared to the control group, and nitrotyrosine levels positively correlated with HbAlc levels [82]. However, even though the levels of oxidative stress markers are higher in patients with type 2 diabetes, some studies do not support the positive correlation between $\mathrm{HbAlc}$ and oxidative stress markers $[83,84]$.

Considering the critical role of oxidative stress in the development of type 2 diabetes, the levels of oxidative stress markers are thought to increase in the prediabetic state. Consistent with this hypothesis, the plasma levels of thiobarbituric acid reactive sub- stances have been shown to positively correlate with body mass index and waist circumference in obese, nondiabetic individuals [85]. Moreover, higher levels of mitochondrial ROS have been detected in the skeletal muscle tissue of obese human subjects as compared with lean controls $[86,87]$. Higher levels of circulating FFAs might be implicated in increased ROS levels in obese subjects, as suggested by previous studies. Two-consecutive fat-rich meals have been shown to increase plasma malondialdehyde levels in healthy young males [88]. Additionally, in nonobese sedentary humans, overfeeding with an HFD for 28 days induced insulin resistance and increased muscle protein carbonylation [89]. Furthermore, increased levels of carbonylated protein negatively correlated with insulin sensitivity in these overfed subjects [89].

As excess ROS are scavenged by the antioxidant system, increased oxidative stress in obese and type 2 diabetic subjects is followed by a reduction in antioxidant levels. Obese patients with body mass indexes above $35 \mathrm{~kg} / \mathrm{m}^{2}$ exhibit low levels of carotenoids and vitamin $\mathrm{E}$ [90]. Lower levels of vitamin $\mathrm{E}$ have been reported in plasma of patients with type 2 diabetes as compared to normal controls [91]. In the Rotterdam Study, the ferric reducing ability of plasma (FRAP) score, an index of dietary antioxidant capacity, was inversely related to the insulin resistance index [92]. Moreover, increased levels of total dietary antioxidant capacity were associated with a reduced risk of type 2 diabetes in a female cohort study [93]. However, not all studies support the close relationship between antioxidant levels and the risk of type 2 diabetes. No association has been found between the serum levels of $\alpha$-tocopherol or $\beta$-carotene and the risk of diabetes in middle-aged males [94]. Moreover, in a cohort study, levels of dietary antioxidants, including vitamin $\mathrm{C}$, vitamin $\mathrm{E}$, carotenoids, flavonoids and flavones, were not associated with the risk of type 2 diabetes in middle-aged male smokers [55].

Additionally, the administration of antioxidants to humans has shown controversial results. Increased dietary intake of $\beta$-carotene for 10 years have been associated with reduced risk of diabetes [95]. Vitamin C intake is associated with a reduced risk of incident diabetes in Japanese women [96]. In contrast, the administration of $\alpha$-tocopherol or $\beta$-carotene does not significantly affect the occurrence of diabetes in males [94]. Moreover, resveratrol-mediated attenuation of ROS production and oxidative damage does not affect HOMA-IR in patients with type 2 diabetes [97].

Based on experimental animal and human studies, oxidative stress is closely linked to type 2 diabetes. However, the antioxidant capacity of the serum or tissue is not consistently related to the risk of type 2 diabetes. Additionally, the administration of antioxidants to prediabetic and diabetic patients has produced inconsistent results. There might be several reasons for this inconsistency. A limit- 
ed number of antioxidants have been assessed for antioxidant capacity in serum. Additionally, it is difficult to assess the antioxidant capacity in insulin-sensitive tissues such as skeletal muscle and adipose tissue in humans. Serum levels of antioxidants are not always consistent with tissue levels. Furthermore, some of the currently used drugs for the treatment of type 2 diabetes have been shown to exert an antioxidant property which may conceal the therapeutic effect of vitamins and natural antioxidants in type 2 diabetes [98]. In most prospective studies, limited types of antioxidants have been used to assess the risk of type 2 diabetes. However, antioxidants still hold promise as potential therapeutic options for the prevention and treatment of type 2 diabetes and its complications. According to Clinicaltrials.gov, 23 clinical trials are recruiting or planning to recruit participants to take part in studies examining the effects of antioxidants on glucose levels or peripheral tissue complications in prediabetic and type 2 diabetic patients (Table 2). Dietary and natural antioxidants from various sources and vitamins are still popular agents for clinical trials, and melatonin is emerging as a potential therapy for type 2 diabetes. Pharmaceuticals targeting prooxidant and antioxidant enzymes, such as $\mathrm{NADPH}$ oxidase inhibitors, xanthine oxidase inhibitors, and SOD mimetics, are actively being developed for the treatment of oxidative stress-related diseases, including type 2 diabetes $[99,100]$.

\section{Conclusion}

Oxidative stress is elevated in obese prediabetic and type 2 diabetic experimental animals and humans. However, although experimental animal studies show promising results, the effects of antioxidant administration on type 2 diabetes in humans are still inconsistent. Nevertheless, clinical trials examining the therapeutic effects of dietary antioxidants and vitamins on type 2 diabetes and its complications are still ongoing. Pharmaceuticals targeting redox regulating enzymes are actively under development, and the successful development of pharmaceuticals might help us understand the therapeutic effectiveness of antioxidants in the treatment of type 2 diabetes.

\section{Acknowledgments}

\section{Conflicts of interest}

No potential conflict of interest relevant to this article was reported.

Table 2. Recruiting and not yet recruiting (August 2020) clinical trials of agents with antioxidant properties targeting type 2 diabetes

\begin{tabular}{|c|c|c|}
\hline Trial start year & Drug & Target condition and disease \\
\hline 2010 & Quercetin & Obesity/type 2 diabetes \\
\hline \multirow[t]{2}{*}{2014} & Blackcurrants/green currants & Type 2 diabetes \\
\hline & Vitamin $\mathrm{E}$ and $\mathrm{C}$ & Type 2 diabetes/fatty liver/obesity/healthy volunteers \\
\hline \multirow[t]{2}{*}{2015} & Grape seed polyphenolic extract and resveratrol & Mild cognitive impairment and prediabetes or type 2 diabetes \\
\hline & Blueberry tea & Type 2 diabetes \\
\hline \multirow[t]{3}{*}{2016} & Melatonin & Prediabetes/obesity \\
\hline & Metadoxine & Nonalcoholic fatty liver disease/prediabetes \\
\hline & Chlorogenic acid enriched coffee & Type 2 diabetes/chronic renal insufficiency \\
\hline 2017 & Vitamin D & Vitamin D deficiency/glucose intolerance/oxidative stress/insulin resistance \\
\hline \multirow[t]{6}{*}{2018} & Hydrolyzed pine nut oil/hydrolyzed pine nut oil and olive oil & Type 2 diabetes/obesity \\
\hline & Green tea extract & Diabetic nephropathy, type 2 \\
\hline & Sanprobi barrier (multispecies probiotic) & Type 2 diabetes/metformin adverse reaction \\
\hline & Transresveratrol & Type 2 diabetes/coronary artery disease \\
\hline & Pentoxifylline & Chronic kidney disease stage 3 and 4/type 2 diabetes \\
\hline & Naturally-sweetened orange juice & $\begin{array}{l}\text { Cardiovascular risk factor/type } 2 \text { diabetes/insulin sensitivity/metabolic } \\
\text { syndrome }\end{array}$ \\
\hline \multirow[t]{5}{*}{2019} & Melatonin/metformin & Prediabetes \\
\hline & $\begin{array}{l}\text { Solarplast (a mixture of antioxidant enzymes and single } \\
\text { antioxidant molecules) }\end{array}$ & Oxidative stress/healthy aging/skin health \\
\hline & Melatonin & Diabetes mellitus \\
\hline & Melatonin & $\begin{array}{l}\text { Metabolic disease/insulin sensitivity/glucose metabolism disorders/type } 2 \\
\text { diabetes/blood pressure/inflammation }\end{array}$ \\
\hline & Olive oil & Type 2 diabetes/platelet dysfunction/postprandial hyperglycemia \\
\hline \multirow[t]{3}{*}{2020} & Docosahexaenoic acid and lutein enriched eggs & Diabetic retinopathy \\
\hline & Vitamin $C, D$, and zinc & Type 2 diabetes \\
\hline & Alpha-lipoic acid & Type 2 diabetes/diabetic polyneuropathy \\
\hline
\end{tabular}




\section{Funding}

This research was supported by grants from the Medical Research Center Program (2015R1A5A2009124) and the Basic Science Research Program (2019R1A2C1088730) through the National Research Foundation of Korea (NRF), funded by the Korean government.

\section{Author contributions}

Conceptualization, Funding acquisition, Validation, Formal analysis, Supervision: SYP; Writing-original draft: SP, SYP; Writing-review \& editing: SP, SYP.

\section{ORCID}

Soyoung Park, https://orcid.org/0000-0002-1674-8940

So-Young Park, https://orcid.org/0000-0002-6018-0440

\section{References}

1. Abdali D, Samson SE, Grover AK. How effective are antioxidant supplements in obesity and diabetes? Med Princ Pract 2015;24:201-15.

2. Forbes JM, Cooper ME. Mechanisms of diabetic complications. Physiol Rev 2013;93:137-88.

3. Di Meo S, Iossa S, Venditti P. Skeletal muscle insulin resistance: role of mitochondria and other ROS sources. J Endocrinol 2017;233:R15-42

4. Facchini FS, Hua N, Abbasi F, Reaven GM. Insulin resistance as a predictor of age-related diseases. J Clin Endocrinol Metab 2001;86:3574-8.

5. Rains JL, Jain SK. Oxidative stress, insulin signaling, and diabetes. Free Radic Biol Med 2011;50:567-75.

6. Li R, Jia Z, Trush MA. Defining ROS in biology and medicine. React Oxyg Species (Apex) 2016;1:9-21.

7. He L, He T, Farrar S, Ji L, Liu T, Ma X. Antioxidants maintain cellular redox homeostasis by elimination of reactive oxygen species. Cell Physiol Biochem 2017;44:532-53.

8. Trujillo M, Ferrer-Sueta G, Radi R. Peroxynitrite detoxification and its biologic implications. Antioxid Redox Signal 2008; 10:1607-20.

9. Cheung PY, Wang W, Schulz R. Glutathione protects against myocardial ischemia-reperfusion injury by detoxifying peroxynitrite. J Mol Cell Cardiol 2000;32:1669-78.

10. Herrera R, Rosen OM. Autophosphorylation of the insulin receptor in vitro. Designation of phosphorylation sites and correlation with receptor kinase activation. J Biol Chem 1986; 261:11980-5.

11. Sun XJ, Rothenberg P, Kahn CR, Backer JM, Araki E, Wilden
PA, et al. Structure of the insulin receptor substrate IRS-1 defines a unique signal transduction protein. Nature 1991; 352:73-7.

12. Hanke S, Mann M. The phosphotyrosine interactome of the insulin receptor family and its substrates IRS-1 and IRS-2. Mol Cell Proteomics 2009;8:519-34.

13. Taniguchi CM, Kondo T, Sajan M, Luo J, Bronson R, Asano T, et al. Divergent regulation of hepatic glucose and lipid metabolism by phosphoinositide 3-kinase via Akt and PKClambda/ zeta. Cell Metab 2006;3:343-53.

14. Alessi DR, James SR, Downes CP, Holmes AB, Gaffney PR, Reese $\mathrm{CB}$, et al. Characterization of a 3-phosphoinositide-dependent protein kinase which phosphorylates and activates protein kinase Balpha. Curr Biol 1997; 7:261-9.

15. Sarbassov DD, Guertin DA, Ali SM, Sabatini DM. Phosphorylation and regulation of Akt/PKB by the rictor-mTOR complex. Science 2005;307:1098-101.

16. Manning BD, Toker A. AKT/PKB signaling: navigating the network. Cell 2017;169:381-405.

17. Imazu M, Strickland WG, Chrisman TD, Exton JH. Phosphorylation and inactivation of liver glycogen synthase by liver protein kinases. J Biol Chem 1984;259:1813-21.

18. Kwon HS, Huang B, Unterman TG, Harris RA. Protein kinase $\mathrm{B}$-alpha inhibits human pyruvate dehydrogenase kinase-4 gene induction by dexamethasone through inactivation of FOXO transcription factors. Diabetes 2004;53:899-910.

19. Sano H, Kane S, Sano E, Mîinea CP, Asara JM, Lane WS, et al. Insulin-stimulated phosphorylation of a Rab GTPase-activating protein regulates GLUT4 translocation. J Biol Chem 2003; 278:14599-602.

20. Cerf ME. Beta cell dysfunction and insulin resistance. Front Endocrinol (Lausanne) 2013;4:37.

21. Kashyap SR, Belfort R, Berria R, Suraamornkul S, Pratipranawatr T, Finlayson J, et al. Discordant effects of a chronic physiological increase in plasma FFA on insulin signaling in healthy subjects with or without a family history of type 2 diabetes. Am J Physiol Endocrinol Metab 2004;287:E357-46.

22. Santomauro AT, Boden G, Silva ME, Rocha DM, Santos RF, Ursich MJ, et al. Overnight lowering of free fatty acids with Acipimox improves insulin resistance and glucose tolerance in obese diabetic and nondiabetic subjects. Diabetes 1999; 48:1836-41.

23. Itani SI, Ruderman NB, Schmieder F, Boden G. Lipid-induced insulin resistance in human muscle is associated with changes in diacylglycerol, protein kinase $\mathrm{C}$, and IkappaB-alpha. Diabetes 2002;51:2005-11.

24. Holland WL, Bikman BT, Wang LP, Yuguang G, Sargent KM, 
Bulchand S, et al. Lipid-induced insulin resistance mediated by the proinflammatory receptor TLR4 requires saturated fatty acid-induced ceramide biosynthesis in mice. J Clin Invest 2011; 121:1858-70.

25. Oakes ND, Bell KS, Furler SM, Camilleri S, Saha AK, Ruderman NB, et al. Diet-induced muscle insulin resistance in rats is ameliorated by acute dietary lipid withdrawal or a single bout of exercise: parallel relationship between insulin stimulation of glucose uptake and suppression of long-chain fatty acyl-CoA. Diabetes 1997;46:2022-8.

26. Arkan MC, Hevener AL, Greten FR, Maeda S, Li ZW, Long JM, et al. IKK-beta links inflammation to obesity-induced insulin resistance. Nat Med 2005;11:191-8.

27. Hotamisligil GS, Peraldi P, Budavari A, Ellis R, White MF, Spiegelman BM. IRS-1-mediated inhibition of insulin receptor tyrosine kinase activity in TNF-alpha- and obesity-induced insulin resistance. Science 1996;271:665-8.

28. Barazzoni R, Zanetti M, Gortan Cappellari G, Semolic A, Boschelle M, Codarin E, et al. Fatty acids acutely enhance insulin-induced oxidative stress and cause insulin resistance by increasing mitochondrial reactive oxygen species (ROS) generation and nuclear factor- $\kappa \mathrm{B}$ inhibitor ( $\mathrm{I} \kappa \mathrm{B})$-nuclear factor- $\kappa \mathrm{B}$ $(\mathrm{NF \kappa B})$ activation in rat muscle, in the absence of mitochondrial dysfunction. Diabetologia 2012;55:773-82.

29. Satapati S, Kucejova B, Duarte JA, Fletcher JA, Reynolds L, Sunny NE, et al. Mitochondrial metabolism mediates oxidative stress and inflammation in fatty liver. J Clin Invest 2015; 125:4447-62.

30. Paglialunga S, Ludzki A, Root-McCaig J, Holloway GP. In adipose tissue, increased mitochondrial emission of reactive oxygen species is important for short-term high-fat diet-induced insulin resistance in mice. Diabetologia 2015;58:1071-80.

31. Chen XH, Zhao YP, Xue M, Ji CB, Gao CL, Zhu JG, et al. TNF-alpha induces mitochondrial dysfunction in 3T3-L1 adipocytes. Mol Cell Endocrinol 2010;328:63-9.

32. Imoto K, Kukidome D, Nishikawa T, Matsuhisa T, Sonoda K, Fujisawa K, et al. Impact of mitochondrial reactive oxygen species and apoptosis signal-regulating kinase 1 on insulin signaling. Diabetes 2006;55:1197-204.

33. Ma J, Nakagawa Y, Kojima I, Shibata H. Prolonged insulin stimulation down-regulates GLUT4 through oxidative stress-mediated retromer inhibition by a protein kinase CK2-dependent mechanism in 3T3-L1 adipocytes. J Biol Chem 2014;289:13342.

34. Nomiyama T, Igarashi Y, Taka H, Mineki R, Uchida T, Ogihara $\mathrm{T}$, et al. Reduction of insulin-stimulated glucose uptake by peroxynitrite is concurrent with tyrosine nitration of insulin recep- tor substrate-1. Biochem Biophys Res Commun 2004;320: 639-47.

35. Zou MH, Hou XY, Shi CM, Nagata D, Walsh K, Cohen RA. Modulation by peroxynitrite of Akt- and AMP-activated kinase-dependent Ser1179 phosphorylation of endothelial nitric oxide synthase. J Biol Chem 2002;277:32552-7.

36. Bonnard C, Durand A, Peyrol S, Chanseaume E, Chauvin MA, Morio B, et al. Mitochondrial dysfunction results from oxidative stress in the skeletal muscle of diet-induced insulin-resistant mice. J Clin Invest 2008;118:789-800.

37. Hiona A, Sanz A, Kujoth GC, Pamplona R, Seo AY, Hofer T, et al. Mitochondrial DNA mutations induce mitochondrial dysfunction, apoptosis and sarcopenia in skeletal muscle of mitochondrial DNA mutator mice. PLoS One 2010;5:e11468.

38. Bhatti JS, Bhatti GK, Reddy PH. Mitochondrial dysfunction and oxidative stress in metabolic disorders - a step towards mitochondria based therapeutic strategies. Biochim Biophys Acta Mol Basis Dis 2017;1863:1066-77.

39. Shin MG, Cha HN, Park S, Kim YW, Kim JY, Park SY. Selenoprotein $\mathrm{W}$ deficiency does not affect oxidative stress and insulin sensitivity in the skeletal muscle of high-fat diet-fed obese mice. Am J Physiol Cell Physiol 2019;317:C1172-82.

40. Heo JY, Cha HN, Kim KY, Lee E, Kim SJ, Kim YW, et al. Methionine sulfoxide reductase B1 deficiency does not increase highfat diet-induced insulin resistance in mice. Free Radic Res 2017;51:24-37.

41. Muscogiuri G, Salmon AB, Aguayo-Mazzucato C, Li M, Balas B, Guardado-Mendoza R, et al. Genetic disruption of SOD1 gene causes glucose intolerance and impairs $\beta$-cell function. Diabetes 2013;62:4201-7.

42. Liu Y, Qi W, Richardson A, Van Remmen H, Ikeno Y, Salmon $\mathrm{AB}$. Oxidative damage associated with obesity is prevented by overexpression of CuZn- or Mn-superoxide dismutase. Biochem Biophys Res Commun 2013;438:78-83.

43. Kang L, Dai C, Lustig ME, Bonner JS, Mayes WH, Mokshagundam S, et al. Heterozygous SOD2 deletion impairs glucose-stimulated insulin secretion, but not insulin action, in high-fat-fed mice. Diabetes 2014;63:3699-710.

44. Lark DS, Kang L, Lustig ME, Bonner JS, James FD, Neufer PD, et al. Enhanced mitochondrial superoxide scavenging does not improve muscle insulin action in the high fat-fed mouse. PLoS One 2015; 10:e0126732.

45. Boden MJ, Brandon AE, Tid-Ang JD, Preston E, Wilks D, Stuart $\mathrm{E}$, et al. Overexpression of manganese superoxide dismutase ameliorates high-fat diet-induced insulin resistance in rat skeletal muscle. Am J Physiol Endocrinol Metab 2012;303:E798805. 
46. Park YS, Uddin MJ, Piao L, Hwang I, Lee JH, Ha H. Novel role of endogenous catalase in macrophage polarization in adipose tissue. Mediators Inflamm 2016;2016:8675905.

47. Piao L, Dorotea D, Jiang S, Koh EH, Oh GT, Ha H. Impaired peroxisomal fitness in obese mice, a vicious cycle exacerbating adipocyte dysfunction via oxidative stress. Antioxid Redox Signal 2019;31:1339-51.

48. Amos DL, Robinson T, Massie MB, Cook C, Hoffsted A, Crain $\mathrm{C}$, et al. Catalase overexpression modulates metabolic parameters in a new 'stress-less' leptin-deficient mouse model. Biochim Biophys Acta Mol Basis Dis 2017;1863:2293-306.

49. Kang L, Lustig ME, Bonner JS, Lee-Young RS, Mayes WH, James FD, et al. Mitochondrial antioxidative capacity regulates muscle glucose uptake in the conscious mouse: effect of exercise and diet. J Appl Physiol (1985) 2012;113:1173-83.

50. Lee HY, Lee JS, Alves T, Ladiges W, Rabinovitch PS, Jurczak MJ, et al. Mitochondrial-targeted catalase protects against high-fat diet-induced muscle insulin resistance by decreasing intramuscular lipid accumulation. Diabetes 2017;66:2072-81.

51. McClung JP, Roneker CA, Mu W, Lisk DJ, Langlais P, Liu F, et al. Development of insulin resistance and obesity in mice overexpressing cellular glutathione peroxidase. Proc Natl Acad Sci U S A 2004;101:8852-7.

52. Loh K, Deng H, Fukushima A, Cai X, Boivin B, Galic S, et al. Reactive oxygen species enhance insulin sensitivity. Cell Metab 2009; 10:260-72.

53. Merry TL, Tran M, Dodd GT, Mangiafico SP, Wiede F, Kaur S, et al. Hepatocyte glutathione peroxidase- 1 deficiency improves hepatic glucose metabolism and decreases steatohepatitis in mice. Diabetologia 2016;59:2632-44.

54. Kim HR, Choi EJ, Kie JH, Lee JH, Seoh JY. Deficiency of glutathione peroxidase- 1 and catalase attenuated diet-induced obesity and associated metabolic disorders. Acta Diabetol 2020; 57:151-61.

55. Wohua Z, Weiming X. Glutaredoxin 2 (GRX2) deficiency exacerbates high fat diet (HFD)-induced insulin resistance, inflammation and mitochondrial dysfunction in brain injury: a mechanism involving GSK-3 $\beta$. Biomed Pharmacother 2019;118: 108940.

56. Cha HN, Park S, Dan Y, Kim JR, Park SY. Peroxiredoxin2 deficiency aggravates aging-induced insulin resistance and declines muscle strength. J Gerontol A Biol Sci Med Sci 2019;74:14754.

57. Kim JH, Park SJ, Chae U, Seong J, Lee HS, Lee SR, et al. Peroxiredoxin 2 mediates insulin sensitivity of skeletal muscles through regulation of protein tyrosine phosphatase oxidation. Int J Biochem Cell Biol 2018;99:80-90.
58. Kim JH, Cha HN, Kim YW, Park SY. Peroxiredoxin 2 deficiency does not affect insulin resistance and oxidative stress in high-fat diet-fed obese mice. Arch Physiol Biochem 2020 Mar 6 [Epub]. Arch Physiol Biochem https://doi.org/10.1080/13813455.202 0.1733026 .

59. Huh JY, Kim Y, Jeong J, Park J, Kim I, Huh KH, et al. Peroxiredoxin 3 is a key molecule regulating adipocyte oxidative stress, mitochondrial biogenesis, and adipokine expression. Antioxid Redox Signal 2012;16:229-43.

60. Chen L, Na R, Gu M, Salmon AB, Liu Y, Liang H, et al. Reduction of mitochondrial $\mathrm{H} 2 \mathrm{O} 2$ by overexpressing peroxiredoxin 3 improves glucose tolerance in mice. Aging Cell 2008; 7:866-78.

61. Nabeshima A, Yamada S, Guo X, Tanimoto A, Wang KY, Shimajiri $S$, et al. Peroxiredoxin 4 protects against nonalcoholic steatohepatitis and type 2 diabetes in a nongenetic mouse model. Antioxid Redox Signal 2013;19:1983-98.

62. Pacifici F, Arriga R, Sorice GP, Capuani B, Scioli MG, Pastore D, et al. Peroxiredoxin 6, a novel player in the pathogenesis of diabetes. Diabetes 2014;63:3210-20.

63. Styskal J, Nwagwu FA, Watkins YN, Liang H, Richardson A, Musi N, et al. Methionine sulfoxide reductase A affects insulin resistance by protecting insulin receptor function. Free Radic Biol Med 2013;56:123-32.

64. Hunnicut J, Liu Y, Richardson A, Salmon AB. MsrA overexpression targeted to the mitochondria, but not cytosol, preserves insulin sensitivity in diet-induced obese mice. PLoS One 2015; 10:e0139844.

65. Nishikawa T, Araki E. Impact of mitochondrial ROS production in the pathogenesis of diabetes mellitus and its complications. Antioxid Redox Signal 2007;9:343-53.

66. Li Y, Soos TJ, Li X, Wu J, Degennaro M, Sun X, et al. Protein kinase $\mathrm{C}$ theta inhibits insulin signaling by phosphorylating IRS1 at Ser(1101). J Biol Chem 2004;279:45304-7.

67. Ju TJ, Kwon WY, Kim YW, Kim JY, Kim YD, Lee IK, et al. Hemin improves insulin sensitivity in skeletal muscle in high fatfed mice. J Pharmacol Sci 2014;126:115-25.

68. Kim BS, Cha HN, Kim YW, Kim JY, Dan JM, Park SY. Inhibition of lipid infusion-induced skeletal muscle insulin resistance by cotreatment with tempol and glutathione in mice. J Pharmacol Sci 2009;110:370-80.

69. Gao M, Zhao Z, Lv P, Li Y, Gao J, Zhang M, et al. Quantitative combination of natural anti-oxidants prevents metabolic syndrome by reducing oxidative stress. Redox Biol 2015;6:206-17.

70. Lebel M, Massip L, Garand C, Thorin E. Ascorbate improves metabolic abnormalities in Wrn mutant mice but not the free radical scavenger catechin. Ann NY Acad Sci 2010;1197:40-4.

71. Telci A, Cakatay U, Kayali R, Erdoğan C, Orhan Y, Sivas A, et al. 
Oxidative protein damage in plasma of type 2 diabetic patients. Horm Metab Res 2000;32:40-3.

72. Piwowar A, Knapik-Kordecka M, Warwas M. Markers of oxidative protein damage in plasma and urine of type 2 diabetic patients. BrJ Biomed Sci 2009;66:194-9.

73. Atli T, Keven K, Avci A, Kutlay S, Turkcapar N, Varli M, et al. Oxidative stress and antioxidant status in elderly diabetes mellitus and glucose intolerance patients. Arch Gerontol Geriatr 2004;39:269-75.

74. Song F, Jia W, Yao Y, Hu Y, Lei L, Lin J, et al. Oxidative stress, antioxidant status and DNA damage in patients with impaired glucose regulation and newly diagnosed type 2 diabetes. Clin Sci (Lond) 2007;112:599-606.

75. Konukoglu D, Turhan MS, Ercan M, Serin O. Relationship between plasma leptin and zinc levels and the effect of insulin and oxidative stress on leptin levels in obese diabetic patients. J Nutr Biochem 2004;15:757-60.

76. Ceriello A, Falleti E, Bortolotti N, Motz E, Cavarape A, Russo A, et al. Increased circulating intercellular adhesion molecule- 1 levels in type II diabetic patients: the possible role of metabolic control and oxidative stress. Metabolism 1996;45:498-501.

77. Dong QY, Cui Y, Chen L, Song J, Sun L. Urinary 8-hydroxydeoxyguanosine levels in diabetic retinopathy patients. Eur J Ophthalmol 2008; 18:94-8.

78. Cakatay U. Protein oxidation parameters in type 2 diabetic patients with good and poor glycaemic control. Diabetes Metab 2005;31:551-7.

79. Cominacini L, Fratta Pasini A, Garbin U, Campagnola M, Davoli A, Rigoni A, et al. E-selectin plasma concentration is influenced by glycaemic control in NIDDM patients: possible role of oxidative stress. Diabetologia 1997;40:584-9.

80. Suzuki S, Hinokio Y, Komatu K, Ohtomo M, Onoda M, Hirai S, et al. Oxidative damage to mitochondrial DNA and its relationship to diabetic complications. Diabetes Res Clin Pract 1999; 45:161-8.

81. Ingram KH, Hill H, Moellering DR, Hill BG, Lara-Castro C, Newcomer B, et al. Skeletal muscle lipid peroxidation and insulin resistance in humans. J Clin Endocrinol Metab 2012;97: E1182-6.

82. Torres SH, De Sanctis JB, de L Briceño M, Hernández N, Finol HJ. Inflammation and nitric oxide production in skeletal muscle of type 2 diabetic patients. J Endocrinol 2004;181:419-27.

83. Akkuş I, Kalak S, Vural H, Caglayan O, Menekşe E, Can G, et al. Leukocyte lipid peroxidation, superoxide dismutase, glutathione peroxidase and serum and leukocyte vitamin C levels of patients with type II diabetes mellitus. Clin Chim Acta 1996; 244:221-7.
84. Lin H, Ye S, Xu J, Wang W. The alpha-lipoic acid decreases urinary podocalyxin excretion in type 2 diabetics by inhibiting oxidative stress in vivo. J Diabetes Complications 2015;29:64-7.

85. Furukawa S, Fujita T, Shimabukuro M, Iwaki M, Yamada Y, Nakajima Y, et al. Increased oxidative stress in obesity and its impact on metabolic syndrome. J Clin Invest 2004;114:1752-61.

86. Anderson EJ, Lustig ME, Boyle KE, Woodlief TL, Kane DA, Lin CT, et al. Mitochondrial H2O2 emission and cellular redox state link excess fat intake to insulin resistance in both rodents and humans. J Clin Invest 2009;119:573-81.

87. Konopka AR, Asante A, Lanza IR, Robinson MM, Johnson ML, Dalla Man C, et al. Defects in mitochondrial efficiency and $\mathrm{H} 2 \mathrm{O} 2$ emissions in obese women are restored to a lean phenotype with aerobic exercise training. Diabetes 2015;64:2104-15.

88. Tushuizen ME, Nieuwland R, Scheffer PG, Sturk A, Heine RJ, Diamant M. Two consecutive high-fat meals affect endothelial-dependent vasodilation, oxidative stress and cellular microparticles in healthy men. J Thromb Haemost 2006;4:1003-10.

89. Samocha-Bonet D, Campbell LV, Mori TA, Croft KD, Greenfield JR, Turner N, et al. Overfeeding reduces insulin sensitivity and increases oxidative stress, without altering markers of mitochondrial content and function in humans. PLoS One 2012; 7:e36320.

90. Reitman A, Friedrich I, Ben-Amotz A, Levy Y. Low plasma antioxidants and normal plasma B vitamins and homocysteine in patients with severe obesity. Isr Med Assoc J 2002;4:590-3.

91. Hasegawa G, Yamamoto Y, Zhi JG, Tanino Y, Yamasaki M, Yano $\mathrm{M}$, et al. Daily profile of plasma \%CoQ10 level, a biomarker of oxidative stress, in patients with diabetes manifesting postprandial hyperglycaemia. Acta Diabetol 2005;42:179-81.

92. van der Schaft N, Schoufour JD, Nano J, Kiefte-de Jong JC, Muka T, Sijbrands EJ, et al. Dietary antioxidant capacity and risk of type 2 diabetes mellitus, prediabetes and insulin resistance: the Rotterdam Study. Eur J Epidemiol 2019;34:853-61.

93. Mancini FR, Affret A, Dow C, Balkau B, Bonnet F, Boutron-Ruault $\mathrm{MC}$, et al. Dietary antioxidant capacity and risk of type 2 diabetes in the large prospective E3N-EPIC cohort. Diabetologia 2018;61:308-16.

94. Kataja-Tuomola MK, Kontto JP, Männistö S, Albanes D, Virtamo JR. Effect of alpha-tocopherol and beta-carotene supplementation on macrovascular complications and total mortality from diabetes: results of the ATBC Study. Ann Med 2010;42: 178-86.

95. Sluijs I, Cadier E, Beulens JW, van der A DL, Spijkerman AM, van der Schouw YT. Dietary intake of carotenoids and risk of type 2 diabetes. Nutr Metab Cardiovasc Dis 2015;25:376-81.

96. Eshak ES, Iso H, Muraki I, Tamakoshi A. Among the water-sol- 
uble vitamins, dietary intakes of vitamins C, B2 and folate are associated with the reduced risk of diabetes in Japanese women but not men. Br J Nutr 2019; 121:1357-64.

97. Seyyedebrahimi S, Khodabandehloo H, Nasli Esfahani E, Meshkani $\mathrm{R}$. The effects of resveratrol on markers of oxidative stress in patients with type 2 diabetes: a randomized, double-blind, placebo-controlled clinical trial. Acta Diabetol 2018;55:34153.

98. Choi SW, Ho CK. Antioxidant properties of drugs used in type 2 diabetes management: could they contribute to, confound or conceal effects of antioxidant therapy? Redox Rep 2018;23:1-24.

99. Dao VT, Casas AI, Maghzal GJ, Seredenina T, Kaludercic N, Robledinos-Anton N, et al. Pharmacology and clinical drug candidates in redox medicine. Antioxid Redox Signal 2015; 23:1113-29.

100. Bonetta R. Potential therapeutic applications of MnSODs and SOD-mimetics. Chemistry 2018;24:5032-41. 